\title{
VIVÊNCIAS EM ATIVIDADES ARTÍSTICO-EXPRESSIVAS: uma prática voltada para o desenvolvimento humano ${ }^{1}$
}

\author{
Flávia Diniz Roldão Balmant* \\ Yara Lúcia Mazziotti Bulgacov**
}

\section{Resumo}

Este trabalho apresenta o relato de uma prática social e educativa, estruturante e inclusiva, desenvolvida nas Oficinas de Artecrescimento e ofertada no Programa de Extensão Integrar, vinculado ao Departamento de Psicologia da Universidade Federal do Paraná. Trata-se de uma atividade desenvolvida junto ao adulto-idoso aposentado (clientela para a qual está voltado o Programa), e aberta à participação conjunta de pessoas que se encontram em outras faixas etárias. Parte de uma abordagem multidisciplinar, que perpassa as áreas da Psicologia Social e Sócio-Histórica, Arteterapia e Educação, apresentando e discutindo conceitos básicos que foram utilizados para construir essa interface de áreas. Discorre sobre uma prática que lança mão das vivências artístico-expressivas como forma de possibilitar o desenvolvimento humano. Relata dois estudos de caso como demonstrativo dos resultados obtidos. Esse trabalho demonstra que as Vivências ArtísticoExpressivas, nas dimensões consideradas, podem potencializar o desenvolvimento das pessoas.

Palavras-chave: Vivências Artístico-Expressivas. Adulto-Idoso. Desenvolvimento Humano. Práticas Sociais Educativas.

1 Trabalho apresentado no XII Encontro Nacional da Associação Brasileira de Psicologia Social (Abrapso)/2003. Encaminhado para publicação na Revista Estudos Interdisciplinares do Envelhecimento, 2004.

* Pedagoga, Especialista em Fundamentos do Ensino das Artes e em Arteterapia. Mestre em Psicologia. Monitora das Oficinas de Artecrescimento no Programa de Extensão Integrar da UFPR (2002-2003). E-mail: aquarelavirtual@hotmail.com

** Professora do curso de Graduação e Pós-Graduação do Mestrado em Psicologia da UFPR. Coordenadora do Programa de Extensão Integrar da UFPR. E-mail:ybulgacov@terra.com.br 


\section{Introdução}

Este trabalho constitui-se no relato de uma prática social e educativa, estruturante e inclusiva, desenvolvida nas Oficinas de Artecrescimento oferecidas no Programa de Extensão Integrar da Universidade Federal do Paraná (UFPR), no segundo semestre de 2002 e primeiro semestre de 2003.

O Programa vem realizando desde 1999, ano de seu início, diversos trabalhos que se articulam por meio de oficinas e palestras com adultosidosos ${ }^{2}$ aposentados, visando promover o desenvolvimento humano na sua totalidade. Dentro de um contexto mais amplo, ele reflete uma tendência atual advinda desde o início da última década do século passado, de preocupação com a inclusão da pessoa idosa no espaço educativo das universidades, visando possibilitar a sua educação permanente. Esse fato pode ser observado conforme a grande expansão das Universidades da ou para $a$ Terceira Idade 3 , de acordo com Cachioni (2003).

No Paraná, tais práticas educativas inclusivas, dentre outras, vêm sendo sistematicamente desenvolvidas pela Universidade Federal do Paraná, de um modo mais amplo, através do Programa de Participação Permanente (PPP). Este programa, criado por Maria do Rosário Knechtel no contexto de uma Política de Recursos Humanos e Assuntos Estudantis da UFPR gestão (1994-1998), conforme a pró-reitora, está voltado para a implementação de uma política que visa abranger todos os segmentos da comunidade universitária interna, com o objetivo de promover o desenvolvimento e a construção permanente da cidadania levando em conta a função social da universidade. (CAMARGO; SANCHES, 1998).

Tal política de recursos humanos foi orientada a partir do conceito de Educação Permanente. O conceito de Educação Permanente foi ressignificado por Maria do Rosário Knechtel em seu livro Educação Permanente: da

\footnotetext{
${ }^{2} \mathrm{O}$ termo adultos-idosos é utilizado aqui para fazer referência a adultos com mais idade, ou seja, adultos com mais de 50 anos, e aos idosos que participaram na Oficina. Cabe destacar que, conforme a Lei 10.741 que dispõe sobre o Estatuto do Idoso, e a Lei n ${ }^{\circ} 8.842$ que trata da Política Nacional do Idoso, considera-se idosa a pessoa com 60 anos ou mais. Como se trabalhou com pessoas com menos idade em conjunto com os idosos, optou-se aqui pelo termo adultos-idosos.

3 Conforme Cachioni (2003), o primeiro programa brasileiro direcionado ao segmento idoso numa instituição superior iniciou suas atividades em 1982, na Universidade Federal de Santa Catarina (UFSC). Já em 1999, conforme Martins de Sá (apud CACHIONI, 2003, p. 79), estes estariam mais ou menos em torno de 140 programas.
} 
reunificação alemã a reflexões e práticas no Brasil, publicado em 1994. Knechtel vai procurar, como afirma Freitag (1994) no prólogo, possíveis respostas e soluções para a superação dos impasses e contradições constatadas na tradição da educação permanente, compreendida amplamente como busca da cidadania, da liberdade e do respeito mútuo entre uma população adulta de uma sociedade moderna. Entende Freitag (1994), a educação permanente como um dos vários instrumentos pedagógicos e políticos, capaz de promover junto aos cidadãos adultos uma melhor compreensão do exercício da cidadania num tríplice registro: o econômico, o político ideológico e o técnico profissional. Entendendo que a Educação Permanente deva ser revalorizada em sua função social e pública em uma democracia que atinja o bem comum dos cidadãos, propõe Knechtel (1994) ações que seriam prioritária a operacionalização de seu conceito, que dentre outras, visariam:

a) dar educação de qualidade a todos (formal, não formal, educação à distância);

b) dar relevância qualitativa à formação dos formadores;

c) contribuir para a reeducação ideológica, política e profissional a todos os brasileiros;

d) educação política a todos;

e) criar políticas e procedimentos através do poder público de modo a socializar os conhecimentos;

f) promover a expansão, assimilação e consolidação de práticas educativas não formais.

Assim afirma a autora, a " [ ... ] Educação Permanente, atingindo todos os domínios da vida em nível da capacidade de cada um, estaria concorrendo, efetivamente, para a construção de um saber necessário ao cidadão, propiciando o máximo de autonomia política e cultural, mantendoo em movimento contínuo, condição necessária para estar sempre ligado ao futuro.”(KNECHTEL, 1994, p. 142).

O PPP pode ser entendido como um programa que possibilita a reintegração dos aposentados e a sua inclusão em um convívio comunitário no ambiente universitário, lhes proporcionando contínuo desenvolvimento e atuação acadêmica. O Programa vem sendo desenvolvido por meio de subprogramas ${ }^{4}$, dentre os quais, está o Programa Integrar ${ }^{5}$. 
Como o próprio nome indica, apesar de ser voltado para uma clientela de adultos-idosos aposentados, o Programa tem o objetivo de promover, também, relações entre as pessoas de diferentes faixas-etárias que desejem participar ${ }^{6}$. As atividades das várias oficinas e palestras são coordenadas por jovens acadêmicos e alunas do curso de Pós-Graduação em Psicologia [que possuem, na sua maioria, entre 20 e 25 anos].

O termo Vivências em Atividades Artístico-Expressivas foi empregado, nesse momento específico, para caracterizar o tipo de atividade desenvolvida na Oficina de Artecrescimento, a saber, experiências grupais em atividades artístico-expressivas voltadas para o fazer, o apreciar e o partilhar sobre arte, sobre si mesmo como pessoa e sobre o mundo em que vivemos, usando os mais diversos meios artísticos.

Grupo é entendido aqui como na perspectiva de Ávila (2001, p. 28), "[ ... ] um lugar de mediação [ ...] um espaço de construção e desenvolvimento da subjetividade [... ] um privilegiado espaço socializador". Também, conforme a perspectiva de Tatagiba e Filártiga (2001, p. 13), para quem um grupo é um espaço "[ . . . o onde se oportuniza um universo de experiências para o desenvolvimento e crescimento das pessoas a partir da descoberta de si e dos outros", bem como o "[... .] crescimento das relações humanas" (TATAGIBA; FILÁRTIGA, 2001, p. 15). Uma ferramenta que facilita a construção de um saber através da participação e do trabalho coletivo . (TATAGIBA; FILÁRTIGA, 2001).

O desenvolvimento dessas vivências nas Oficinas de Artecrescimento tinha por objetivo possibilitar um espaço para o desenvolvimento integral dos participantes, contemplando, de modo especial:

a) o estímulo à descoberta pessoal de que a atividade imaginativa e criativa, e a experiência estética por meio da fruição de obras de arte, podem tornar-se fontes de prazer, descarga de energias não utilizadas (VYGOTSKY, 1999) e, ao mesmo tempo, fontes de ampliação do repertório cultural, da educação emocional-afetiva e estética, tornando-se, em última instância, potencializadoras do desenvolvimento humano;

4 Conforme Fedeger (2004), estes sub-programas são: Professor-Sênior, Técnico-Sênior, Educação Permanente Interidades, e o Programa de Preparação para a Aposentadoria (PPA) que foi desenvolvido durante os anos de 1995 a 1999.

${ }^{5}$ Para maiores detalhes sobre o Programa Integrar, vide, Bulgacov; Castiglia (2003).

${ }^{6}$ Pesquisa realizada por Palhares (2003, p. 21) mostra, entretanto, que "[ . . . ] mais de 50\% dos inscritos encontra-se na faixa de 61 e 75 anos." 
b) a constituição de um espaço para a partilha social das emoções (RIMÉ, 1993) e o desenvolvimento pessoal no âmbito das relações interpessoais e intergeracionais, por meio da expressão artística, afetiva e emocional;

c) a construção de um espaço para a exploração do autoconhecimento e a ampliação da autoconsciência.

\section{Metodologia}

A metodologia de trabalho utilizada foi a de Vivências ArtísticoExpressivas (BALMANT, 2003a) em pequenos grupos, desenvolvidas nas Oficinas de Artecrescimento (BALMANT, 2003b) durante o segundo semestre letivo de 2002 e o primeiro semestre letivo de 2003.

O embasamento teórico que sustentou essa prática adveio de um referencial multidisciplinar perpassando as áreas da Psicologia Social e SócioHistórica, da Arteterapia e da Educação.

Na Psicologia Social e Sócio-Histórica, sustentou-se a visão do ser humano como um ser em movimento (LANE; CODO, 1993; CIAMPA, 1996), um ser histórico e socialmente constituído (LANE, 1981; LANE; CODO, 1993). Também, a importância das funções emoção e imaginação, na constituição e no desenvolvimento humano respectivamente. Conforme Lane e Sawaia (1995), a emoção é uma função dentre outras, que constitui o psiquismo humano. Ela é parte integrante dos processos de aprendizagem (CAMARGO, 1997; GONZÁLEZ REY, 2002, 1995). Por outro lado, como apontou Vygotsky (1990), a imaginação é uma função vital, necessária, e não apenas um "[ ... ] divertimento caprichoso do cérebro" (p. 15). "Ela é uma função de suma importância na conduta e no desenvolvimento humano, sendo um meio de ampliar a experiência da pessoa." (VYGOTSKY, 1990, p. 20). Como é possível perceber através de escritos de Vygotsky (1990, 1999, 2001), a arte mobiliza ambas funções. Assim, acredita-se que a prática das atividades artístico-expressivas é um meio de possibilitar o exercício e o trabalho com a imaginação e a emoção (dentre outros aspectos), com vistas ao desenvolvimento humano.

Pensar a mediação artística como um método de diagnóstico e tratamento ${ }^{7}$, é uma prática que já tem sido desenvolvida pela Arteterapia em suas diversas abordagens. $\mathrm{O}$ trabalho de diversos autores atestam essa prática que tem sido desenvolvida de modo especial a partir do início século XX na 
América do Norte, e do final deste no Brasil.. (CARVALHO, 1995; BELLO, 1998; RHYNE, 2000; RILEY, 1998; ROGERS, 1993). A partir do contato com a obra destes autores que relatam tais práticas, e ao mesmo tempo, numa tentativa de distanciar-se delas construindo um caminho próprio a partir da concepção teórica que embasou esta prática, refletiu-se como a mediação artística poderia ser usada de modo singular com este grupo, constituindo-se num modo de potencialização do desenvolvimento humano por meio da prática educativa, a partir da prática das atividades artístico-expressivas. Considerando estas como atividades sócio-educativas, nas quais se processa a educação pela cultura, ou seja, por meio do contato das pessoas com produtos culturais artísticos diversos, e das relações das pessoas entre si.

Os teóricos que embasaram o trabalho no que tange à questão da Educação foram Bruner (2001), para quem a cultura " [ ... ] molda a mente dos indivíduos" (p. 16), origina significados, e fornece as ferramentas para a organização e o entendimento do mundo. Brandão (1985), que destaca que "[... ] não há uma forma única nem um único modelo de educação; a escola não é o único lugar onde ela acontece e talvez nem seja o melhor; o ensino escolar não é a sua única prática e o professor profissional não é o seu único praticante” (p. 9). Vygotsky (1989), para quem “[ . . . ] aprendizado não é desenvolvimento" (p. 101), mas ele põe em movimento vários processos de desenvolvimento. González Rey $(2002,1995)$ para quem o processo de educação é um processo constitutivo do desenvolvimento humano; e Knetchel (1994), que destaca a importância de uma educação permanente do ser.

Com relação aos procedimentos adotados, no segundo semestre de 2002 foram abertas dez vagas para esta oficina, sendo todas preenchidas por adultos-idosos na faixa etária entre 56 e 85 anos. No primeiro semestre de 2003 foram abertas dez vagas, cinco delas destinadas a adultos-idosos, e cinco para jovens, as quais foram preenchidas por cinco adultos-idosos na faixa-etária entre 56 e 77 anos e um jovem de 28 anos.

Foram desenvolvidos 18 encontros semanais, com duração de duas horas cada, em 2002; e 12 encontros de uma hora e meia cada, em 2003. Em 2002, as oficinas foram também o espaço em que desenvolvi meu Estágio em Arteterapia, como parte do Curso de Especialização em Arteterapia. Assim, os procedimentos adotados basearam-se em referencial teórico advindo dessa área do conhecimento, em diálogo com o referencial teórico

Vide Estatuto da Associação Brasileira de Arteterapia. Disponível em $<$ www.arteeterapia.com.br>. Acessado em 13-12-2001. 
da Psicologia Sócio-Histórica. Já em 2003, buscou-se realizar um trabalho voltado para a investigação do uso das manifestações culturais artísticas como forma de educação permanente, voltada para a promoção do desenvolvimento humano integral. ${ }^{8}$

As vivências se efetivaram mediante atividades artístico-expressivas desenvolvidas, utilizando os mais diversos meios:

a) apreciação de músicas, vídeos e poesias;

b) criação e exploração de movimentos espontâneos, exercitando a liberdade corporal ao som de uma música;

c) apreciação de obras-de-arte por meio de visitas a museus ou do contato com reproduções de obras-de-arte;

d) criação de poesias e estórias espontâneas;

e) produção de desenhos, pinturas e colagens.

As Vivências Artístico-Expressivas ocorreram no contexto dessas oficinas, organizadas em três momentos específicos:

a) 1' momento: "Aconchegando" (momento de chegada, ambientação e aquecimento dos participantes). Duração de aproximadamente 10 a 15 minutos;

b) $\mathbf{2}^{\mathbf{0}}$ momento: "Laborando e Elaborando" (momento voltado para a realização de trabalhos expressivos e criativos, através dos quais estimulavam-se os participantes à expressão pessoal pela exploração de meios artísticos diversos, incluindo linguagens verbais e não-verbais). Duração de aproximadamente 30 a 50 minutos;

c) $3^{\mathbf{0}}$ momento: "Encerramento" (momento de partilha, em grupo, acerca das atividades realizadas. O diálogo e a reflexão eram, neste momento, os meios privilegiados. A participação de todos era sempre estimulada, para que falassem sobre sua produção ou oferecessem alguma contribuição sobre algo colocado por outra pessoa do grupo). Duração de aproximadamente 10 a 20 minutos.

8 Educação voltada para o desenvolvimento integral, é compreendida, aqui, à partir de González Rey (1995, p. 2) que escreve: “[ . . . ] La educación es un proceso orientado al desarrollo pleno de la persona, que estimula la expresión auténtica, franca e interesada del escolar dentro del cual este simultáneamente construye conocimientos y se desarrolla en planos diversos como persona". 


\section{Resultados}

Dois casos foram selecionados como demonstrativo dos resultados alcançados nestas Oficinas. Eles tratam do movimento do processo de desenvolvimento pessoal ocorrido com duas participantes. Os mesmos serão explicitados a seguir nos resultados.

\subsection{O Processo de Virgínia: a mediação artística como caminho para a auto-expressividade e aquisição de novas idéias}

Virgínia é uma mulher de 56 anos. De aparência calma, tímida, sua paixão são sua sobrinha, que morou com ela por alguns anos, bem como os seus cachorros e gatos. Foi professora alfabetizadora por muito tempo e cursou pedagogia. Ela veio ao grupo no segundo encontro. Chegou um pouco atrasada ao encontro, quando já estávamos realizando uma dinâmica. Esta consistia em, ao som de uma música, desenhar livremente sobre uma folha em branco, de olhos fechados e sem tirar o lápis da folha durante toda a música ou pelo tempo que achasse suficiente. Ofereci-lhe uma folha de papel e pedi que escolhesse uma cor, da caixa de lápis de cor, para trabalhar. Chamou-me a atenção o fato de que, em face da proposta de desenhar movimentando livremente o lápis sobre o papel, Virgínia desenhou usando linhas sempre retas e bastante proporcionais, formando um labirinto. Observei que ela estava com dificuldades para se soltar e se expressar livremente sobre a folha de papel.

Seria essa uma imagem da sua realidade interior?'

Depois, ao final da oficina, ela afirmou: "Quando cheguei minha vida estava como um labirinto". Em uma das dinâmicas finais, solicitou-se a cada participante que construísse uma mala de cartolina e, dentro desta mala, fizesse uma colagem, sendo que de um dos lados da mala iríamos colar algo que ilustrasse a seguinte expressão: "Assim eu cheguei aqui e isso eu trouxe para compartilhar", e, do outro lado, expressaríamos a frase: "Isso eu vou levando dessa experiência". A mala de Virgínia continha, para ilustrar a primeira frase, uma mulher colocando o dedo sobre a boca, fazendo sinal de

\footnotetext{
9 Vygotsky, em sua obra La imaginacion y el arte en la infancia $(1990$, p. 21), diz que "[ ...] assim como as pessoas aprenderam a manifestar, mediante expressões externas, seu estado interior, também as imagens da fantasia servem de expressão, ou linguagem interior, dos nossos sentimentos."
} 
silêncio, e, abaixo dela, uma imagem muito significativa de um nó, que ela havia recortado e colado naquele local. Ao falar sobre essa imagem, no momento de partilhar sobre seu trabalho com o grupo, ela afirma: "Eu cheguei silenciosa. Trouxe meus medos, trouxe minhas dores, tentando compartilhar... não só na alegria como na dor. Trouxe também os nós da vida, tímida, tentando desabrochar".

Virgínia chegou bastante introvertida, mas o trabalho desenvolvido pôde lhe proporcionar oportunidades de se abrir um pouco mais e partilhar um pouco de si; desejo que ela trazia consigo, embora tivesse dificuldade, pelo que ela mesma menciona - a timidez. Para ilustrar a frase "isso eu trouxe para compartilhar", ela usa a imagem de uma radiola antiga, da qual sai uma língua; mas há um detalhe: a língua está amarrada formando um nó na ponta. Ao lado da figura ela escreve: "perguntas, muitas perguntas, algumas soluções pelas experiências vividas".

Virgínia coloca com grande clareza o que trazia, pois não era de falar muito. Algumas das suas colocações, quando se expressava, mostravam sua vivência ou experiência de vida. Contudo, o nó na ponta da língua foi interpretado a partir de uma análise geral do seu processo, que indicava sua dificuldade para se expressar com mais liberdade.

Com o passar do tempo, pude notar que ela foi se soltando e participando de modo mais efetivo no grupo. Nessa dinâmica da mala, ao final do nosso trabalho, ela ilustrou a frase "Isso eu vou levando dessa experiência" com o recorte e colagem de uma frase, em letras bem grandes, que dizia: "As boas idéias", ao que ela acrescentou a palavra "Grupais".

Foi possível, então, perceber a importância do trabalho grupal para ela. Parece que, dada a sua timidez, Virgínia tinha a tendência de falar menos e ouvir mais, e o trabalho grupal contribuiu para a sua experiência de vida. Vale lembrar que o silêncio também é uma forma de comunicação, a qual pode ter muitos significados. No caso de Virgínia, ele pode ser interpretado como uma dificuldade de se expressar livremente. Entretanto, por meio das vivências artístico-expressivas ela pôde vivenciar um espaço que lhe permitiu - pelas atividades realizadas e pelos diálogos em grupo - trabalhar essa dificuldade.

Na entrevista final, realizada com os participantes ao encerramento dos trabalhos, quando lhe perguntei se achava que a participação nesse tipo de atividade ajuda uma pessoa a se desenvolver, ela respondeu: "Ajuda... ou se não ajuda pelo menos brota alguma coisa que ficou lá no fundo, que 
não foi trabalhada por várias razões, né?... Efloresceu". Quando perguntei de que forma prática a participação na oficina ajudou-a a se desenvolver, ela disse: “Ô, Flávia... especificamente... só se for na questão da poesia, que eu não sabia que sabia escrever poesia e... saiu poesia” "[risos prazerosos].

É importante observar, relativamente à Virgínia, que se antes ela tinha certa dificuldade para se expressar, devido à timidez, agora estava se expressando não apenas verbalmente, como ocorria nas trocas em grupo [agora com mais intensidade que no início do processo], mas também por meio de outras formas, como a poesia, o desenho. Ressalte-se que, no segundo encontro do qual ela participou, solicitei que cada participante escrevesse uma poesia breve, ou um pensamento. Ela escreveu uma poesia sobre não saber fazer poesia, para a qual deu o título " $A$ poesia que não sei fazer", acompanhada de um desenho extremamente expressivo a respeito dessa sua experiência: uma pessoa com uma enorme boca aberta, mostrando, com isso, a dificuldade que foi, para ela, conseguir realizar essa atividade.

No quinto encontro, a temática a ser trabalhada era "Criando o meu auto-retrato". No segundo momento da oficina, o Laborando e Elaborando, pedi aos participantes que, através do desenho, criassem um auto-retrato. Poderia ser um desenho que representasse a sua imagem, ou alguma coisa que o identificasse. Virgínia escolhe giz de cera e desenha um rosto. No momento da partilha em grupo sobre essa atividade, ela fala sobre seus cabelos. Diz tê-los desenhado crespos, mas que não gosta deles assim, como são, e que os prefere lisos [como quando faz 'escova']. Eu digo: “Mas se você não gosta deles assim, por que os fez assim? Ela responde: “Mas... É só um desenho, quem sabe eu já até os aceitei assim”. Pedi, então, que ela levasse seu desenho para casa e dialogasse ${ }^{10}$ com ele durante a semana; se quisesse, poderia deixá-lo como estava, ou poderia retrabalhá-lo acrescentando-lhe detalhes, recortando, pintando por cima, enfim, modificando-o como desejasse. Ela levou-o e trouxe na semana seguinte, com o cabelo modificado: havia colado papel camurça, representando o cabelo bem arrumado e com um grande enfeite na lateral. Isso ocorreu no sexto encontro.

\footnotetext{
${ }^{10}$ A idéia de diálogo com o desenho é utilizada no sentido de se refletir sobre a própria criação. Vê-la, e deixar que ela, por si só, possa transmitir sua mensagem ao fruidor, que reflete sobre qual a mensagem que ele transmitiu naquela criação, qual o sentimento/emoção ali materializados. Como afirma Vygotsky (1990), “[ . . . ] las imágenes de la fantasia prestan también lenguaje interior a nuestros sentimientos...” (p. 21). Assim, o diálogo com as imagens que criamos pode nos auxiliar em sua compreensão e, assim, no avanço de nosso desenvolvimento pessoal.
} 
Na semana anterior a este sexto encontro, eu havia resolvido modelar em argila, uma imagem que pudesse materializar o modo como eu a estava percebendo. Isso por que, eu ficava intrigada com a forma como ela se colocava diante das coisas e do próprio trabalho que estávamos desenvolvendo. Ela me transmitia uma profunda sensação de viver sentimentos contraditórios, como alguém que deseja ir adiante, mas se detém, parada, observando e indagando. Mexendo com a argila, a imagem que me veio foi a de uma cadeira e um grande ponto de interrogação colocado sobre ela. Modelei minha escultura objetivando tal percepção. Era assim que eu a via. Alguém que estava sentada observando o que se passava no grupo [na vida?]. Sem se abrir demais, sem se levantar para dar um passo, fazer uma ação. Como que se perguntando algo. Não como se demonstrasse forte resistência, mas grandes indagações. Assim, foi muito interessante quando, numa das dinâmicas finais, ela afirmou que chegou ao grupo trazendo perguntas e mais perguntas. Pude confirmar, pela sua fala, uma percepção que eu já havia tido do seu processo.

Parece-me que Virgínia começou a se abrir mais a partir do sexto encontro. Por coincidência ou não, foi nesse encontro que ela trouxe o trabalho do auto-retrato com o cabelo modificado, "bem arrumado", como ela mesma disse. Ela havia feito, em casa, a ação de colar, por cima, a representação de um novo visual ao seu cabelo. Trata-se da ação de re-construir aquilo com que se tem dificuldade. De agir sobre a vida.

Para Wertsch"11, apud Aguiar (2002, p. 101), "Para Vigotski o signo não deve ser compreendido simplesmente como uma ferramenta que transforma o mundo externo. Diferentemente dos instrumentos, orientados para regular objetos externos que na realidade constituem condutores da influência humana sobre o objeto da atividade, os signos são orientados para regular as ações sobre o psiquismo das pessoas".

Simbolicamente, Virgínia havia feito uma ação para transformar aquilo com o qual ela não estava satisfeita - dentro das possibilidades e dos recursos de que ela dispunha -, até que ficasse do jeito que ela queria. Essa ação pode ser interpretada como um símbolo do seu movimento interior, naquele momento da sua vida, de se abrir e trabalhar algumas de suas questões, como a expressividade.

${ }^{11}$ WERTSCH, J. Vygotski y la formación social de la mente. Barcelona: Paidós, 1988. P. 94. Apud Aguiar, 2002, p. 101. 
Quando, ao final dos trabalhos, Virgínia compartilha com o grupo que está levando boas idéias grupais, não se sabe precisamente quais são estas idéias, uma vez que ela não entrou em detalhes, mas, pela sua fala, percebe-se que deve ter encontrado algumas respostas ou novos caminhos para buscar respostas às suas indagações. Isso implica que, através dessa experiência, ela ampliou seu repertório, construindo uma mais ampla leitura de mundo.

\subsection{O Processo de Débora: da incerteza para o resgate da auto- confiança, da criatividade e da expressividade pessoal}

Débora é artesã e professora aposentada. Tem 77 anos e é viúva. Mora com sua filha, o genro e um neto. É uma pessoa bastante falante e de um espírito positivo. Veio ao grupo quando estávamos no segundo encontro.

Nos primeiros encontros ela se colocava no grupo, sempre muito falante, mas sem se abrir muito. Ia sempre produzindo as suas criações conforme eram feitas as propostas de trabalho ao grupo, e fazia até mais do que era solicitado, visto que ela continuava a criar em casa [especialmente poesias], entre os intervalos dos encontros. $\mathrm{Na}$ verdade, foi apenas no penúltimo encontro que pude compreender melhor a profundidade do valor desta experiência para ela.

Durante todo o nosso trabalho, em nenhum momento ela comenta sobre alguma dificuldade que gostaria de superar, ou sobre algum aspecto que gostaria de desenvolver usando a mediação artística como forma de desenvolvimento pessoal. Os temas de suas poesias eram a natureza, o amor, a felicidade. Houve até uma poesia, que ela fez no dia das eleições, que tratava de questões relacionadas à política. Ela parecia uma pessoa em plenitude. Mas, como se sabe que o processo de desenvolvimento é um movimento constante, e dura a vida toda, certamente haveria algo em que o trabalho que desenvolvíamos poderia tocá-la de modo particular e fazê-la avançar. Embora Débora não falasse muito a respeito de como ela estava sentindo a vivência desta experiência, também não faltava aos encontros, $o$ que era um sinal de que estava se beneficiando do nosso trabalho de algum modo; só não era possível perceber como.

Algo em Débora que me chamava a atenção é que ela produzia muitas poesias nos encontros e em casa. Assim, pensei que ela já escrevesse há algum tempo. No final do nosso trabalho, quando fiz uma entrevista com 
cada participante, fiquei surpreendida com sua fala. Uma das perguntas que lhe fiz foi se ela considerava que a participação nesse tipo de trabalho ajuda a pessoa a se desenvolver. Ela responde que sim, e muito. Quis saber, então, de que modo a participação nesse trabalho ajudou-a a crescer:

"Ajudou mentalmente eu criar palavras, estórias... tudo isso. Foi uma coisa que vai ficar documentada no meu 'eu', e também até no desenvolvimento para escrever, porque a gente quando fica em casa a gente escreve pouco, por mais que você queira escrever - porque eu nunca deixei de escrever um pouco -, mas você não escreve como eu estou escrevendo agora".

Mas você fazia algumas poesias já? - perguntei. Ela respondeu:

"Há muito tempo... pouca coisa! Eu fiz uma poesia quando o meu marido faleceu. Ele faleceu dia 3 de maio de 1991, e eu fiz uma poesia dia 7 de maio, que foi aniversário dele. Assim... fiz uma poesia, mas nem mostrei para ninguém, enfiei na gaveta. De vez em quando eu me sentava no meu quarto e escrevia um poema, mas ao mesmo tempo eu... ou é lixo ou gaveta [gesticulando e dizendo que ela ou a jogava fora ou a guardava]. Eu não tinha coragem de expor".

E agora? - eu perguntei.

"Agora não, agora eu faço e mostro. Sabe, eu exponho, eu leio para o meu... leio em casa para minha filha, todo trabalho que eu faço aqui eles têm conhecimento. Ainda tem uma coisa importante... eles estão gostando muito. Estão achando que eu mudei. Quer dizer, eu nunca fui uma pessoa fechada, nem assim... triste, nem... sabe, estresse eu não tenho, nunca tive, mas isso ainda melhorou mais um pouquinho a minha... como é que se diz?... Tudo. Meu bem-estar, minha maneira de falar, de contar, de brincar... porque abre caminhos, né?... é realmente uma abertura de caminho".

Indaguei se ela havia considerado importantes as partilhas que havíamos feito em grupo sobre os trabalhos que realizávamos, e sobre como 
estava sendo, para cada um, participar dos encontros e fazer os trabalhos propostos.

"Tem bastante [importância]. Começa que... o contato com outras pessoas, a convivência, a discussão de assuntos, e tudo o que podemos perceber no semelhante, no companheiro... e a amizade que a gente faz, e também com a orientadora, porque isso é uma coisa muito importante, a gente sentir que alguém está... está se interessando pelo que nós fizemos, o que nós fazemos." 12

Nas falas de Débora, é possível ir constatando a grande importância da relação grupal no seu processo de desenvolvimento. Não apenas o que fazemos (as atividades artístico-expressivas) tem implicações no desenvolvimento da pessoa, mas também como fazemos, ou seja, a qualidade das relações grupais também influi nesse desenvolvimento pessoal. Isto evidencia-se em outra fala de Débora, quando comenta sobre a experiência de produzir a primeira poesia e, depois, partilhá-la com o grupo: "Então foi assim... a primeira visita que eu fui com você [referindo-se a uma visita que fizemos a uma exposição de quadros numa Galeria, em que, depois, solicitei que cada pessoa escrevesse uma poesia a partir dessa experiência estética] já abriu para mim fazer uma poesia que foi admirada, eu tive até palmas, todo mundo gostou e dai eu estou fazendo mais coisas...". Nessa fala é possível perceber a importância central do papel das relações grupais no resgate de sua autoconfiança, criatividade e expressividade pessoal.

Na dinâmica avaliativa final, cada participante utilizou a colagem para ilustrar as três questões: "Assim eu cheguei"; "Isso eu trouxe para compartilhar"; e "Assim eu estou saindo daqui, ou seja, isto eu vou levando dessa experiência". Ela diz: "Olha, eu fiz uma figura, ${ }^{13}$ desculpe que foi uma figura masculina [ela explica que não tinha encontrado nenhuma imagem de figura feminina que estivesse de uma forma que lhe agradasse]. Ela diz: $E u$

${ }^{12}$ No final desta sua fala, percebe-se a importância da qualidade da relação que se estabelece nesse tipo de atividade, como forma de possibilitar condições para que possa ocorrer um processo de desenvolvimento. González Rey (1995) já havia salientado a importância de o educador procurar criar um clima de diálogo, segurança e respeito mútuo no processo educativo, permitindo que o diálogo transcorra em um ambiente emocional são, participativo e disciplinado, visando estimular o desenvolvimento da personalidade.

13 A expressão "eu fiz uma figura" foi uma forma de se expressar. Na verdade, ela não havia feito, mas havia escolhido, recortado e colado aquela figura, visto que era um trabalho de recorte e colagem. 
cheguei numa incerteza se iria realmente desenvolver algum trabalho" [e mostra a figura escolhida: uma pessoa numa cadeira de rodas]. E ela continua dizendo: "Mas passado uns dias... eu tive confiança..." [Enquanto fala, mostra a segunda imagem que ela colou para ilustrar sua resposta: duas pessoas apertando as mãos]. E continua falando enquanto aponta para a outra figura que usou na colagem [a de uma pessoa com semblante radiante]: “...e... a vitória. Porque eu vou sair daqui sorrindo". Cabe ressaltar que Débora, embora tenha escolhido a imagem de uma pessoa na cadeira de rodas para usar em sua colagem, não é deficiente física. Entende-se que ela usou essa imagem com o intuito de expressar o modo como se via quando chegou ao grupo. É uma imagem simbólica, que possivelmente representava seu estado interior naquele momento. Lembro-me dos primeiros encontros, depois que ela terminava de fazer suas criações, na sala ou em casa, quando ela sempre perguntava se era assim que eu queria, como se houvesse um modo certo de se fazer, e ela quisesse fazer certo. Lembro-me de que eu sempre buscava que ela pudesse perceber que não havia certo ou errado. O importante é que ela pudesse expressar-se de tal modo que sua criação lhe agradasse.

Essa minha postura com relação à sua atitude de buscar aprovação, tinha o objetivo de que ela própria pudesse perceber que na vida também é assim. Não há o certo ou o errado; há o diferente. Há várias formas diferentes de ser, e vários caminhos por meio dos quais nos colocamos na vida, e assim construímos a nossa vida e nos expressamos como pessoas. Eu esperava que ela vencesse a insegurança de fazer algo errado e pudesse recuperar sua autoconfiança para fazer, criar, produzir e expressar-se livremente.

Débora mostrou ter conseguido superar - ao menos em parte algumas inseguranças que a impediam de criar e mostrar suas criações para outras pessoas, e também a necessidade de buscar a aprovação destas. Ela passou a criar muitas poesias. Criava para si, da forma como desejasse, e nos meses finais do nosso trabalho já não se preocupava tanto com o certo e o errado. Criava porque lhe dava prazer. Ela foi quem mais produziu poesias no grupo. Encontrou na poesia um espaço de expressão pessoal. Ela participou desta oficina somente no segundo semestre de 2002, pois quando a oficina foi oferecida, em 2003, não teve condições de participar; entretanto, tenho notícias de que continua elaborando suas poesias e atualmente tem sido convidada por instituições da cidade de Curitiba a compartilhá-las, lendoas em alguns eventos. 


\title{
5 Considerações Finais
}

Esse trabalho demonstrou, através dos casos exemplificados anteriormente, que as Vivências Artístico-Expressivas podem potencializar o desenvolvimento das pessoas que com elas se envolvem, possibilitando:

a) a ampliação do autoconhecimento e da autoconsciência pessoal;

b) a descoberta de novos canais para que se construa uma leitura mais ampla de mundos possíveis, devendo-se destacar que a experiência grupal pode funcionar como um desses canais;

c) o exercício e o desenvolvimento da imaginação e da criatividade;

d) a objetivação, elaboração e partilha social de emoções;

e) a ampliação das possibilidades de comunicação das pessoas por meios poéticos, verbais e não-verbais;

f) a redescoberta das capacidades criativas e $\operatorname{produtivas~}{ }^{14}$ por parte do adulto-idoso;

g) a abertura de novos caminhos criativos para a inserção do adultoidoso na sociedade, por via de uma atividade produtiva cujo significado está centrado na produção cultural e na dimensão estética da humanidade.

\section{EXISTENCES IN ARTISTIC-EXPRESSIVE ACTIVITIES: practicing human development}

\begin{abstract}
This work is the report of a social and educational practice, structuralized and inclusive, developed at the Workshops of Art-Growth and offered in the Program Extension to Integrate, linked to the Department of Psychology of the Federal University of Paraná. It is an activity developed with retired senior-adults (customers for whom the Program is made), and open for the participation of people of all age groups. It has a multidisciplinary approach, which involves the areas of Social and Socio-historical Psychology, Art Therapy and Education, presenting and discussing the basic concepts

${ }^{14} \mathrm{O}$ termo capacidades produtivas, aqui utilizado, refere-se à produção de conhecimento e história (pessoal e social).
\end{abstract}


that were used to build up this interface of areas. It talks about a practice that uses the artistic-expressive experiences as form of promoting the human development. This work reports two studies of cases to demonstrate the obtained results. This paper shows that the Artistic-expressive Existences, in the considered dimensions, can increase the potentiality of people development. Keywords: Artistic-Expressive Experiences. Aged-Adults. Human Development. Socio-Educational Practices.

\section{REFERÊNCIAS}

AGUIAR, W. M. J. Consciência e Atividade: categorias fundamentais da Psicologia Sócio-Histórica. In: BOCK, A. M. B.; GONÇALVES, M. G. M.; FURTADO, O. Psicologia Sócio-Histórica. 2. ed. São Paulo: Cortez, 2002. P. $95-110$.

ÁVILA, M. F. Por que el grupo en la Psicología Social? Revista Cubana de Psicología, Habana: Universidad de la Habana, v. 18, n. 1, p. 28-33, 2001.

BALMANT, F. D. R. Vivências Artístico-Expressivas e Produção da Identidade: um estudo com jovens acadêmicos e adultos-idosos aposentados. 2003. 25 f. Projeto de Dissertação (Mestrado em Psicologia) - Programa de Pós-Graduação, Universidade Federal do Paraná, Curitiba, 2003a.

- Mediações Artísticas e Vivência Grupal como Elementos Potencializadores para o Contínuo Desenvolvimento Humano Integral. 2003. 82 f. Monografia (Especialização em Arteterapia) - Instituto Superior de Ensino, Pesquisa e Extensão, Curitiba, 2003b.

BELLO, S. Pintando sua Alma: método de desenvolvimento da personalidade criativa. Brasília: UNB, 1998.

BRANDÃO, C. R. O que éEducação. São Paulo: Abril Cultural; Brasiliense, 1985.

BRUNER, J. A Cultura da Educação. Porto Alegre: Artmed, 2001. 
BULGACOV, Y. L. M. et al. Programa de Preparação para Aposentadoria: uma política de desenvolvimento humano. Revista Interação, Curitiba, v. 3, p. 79-94, jan.-dez.,1999.

BULGACOV, Y. L. M.; CASTIGLIA, F. Z. Dialogando com os Princípios de uma Abordagem Substantiva da Organização. Revista Psicologia Organizações e Trabalho, Florianópolis, v. 3, n. 2, jul.-dez., 2003.

CACHIONI, M. Quem Educa os Idosos? Um estudo sobre professores da universidade da terceira idade. Campinas: Alinea, 2003.

CAMARGO, D. As Emoções no Processo de Aprendizagem. 1997 - Tese. (Doutorado em Psicologia). Pós-Graduação em Psicologia Social, Pontifícia Universidade Católica de São Paulo, São Paulo, 1997.

CAMARGO, M. A. C.; SANCHES, M. G. G. (Org.). UFPR Avaliação: Política de Recursos Humanos na Universidade Federal do Paraná. In:

Tempo, Lugar, Sujeito e Condições de Trabalho: uma construção coletiva. Curitiba: UFPr, 1998. P. 25- 46.

CARVALHO, M. M. M. J. (Coord.). A Arte Cura? São Paulo: PSY II, 1995.

CIAMPA, A. C. A Estória de Severino e a História de Severina: um ensaio de Psicologia Social. 5. ed. São Paulo: Brasiliense, 1996.

FEDEGER, A. Relação Intergeracional: concepções e (re)significados da atividade humana produtiva. 2004. Dissertação (Mestrado em Psicologia) Pós-Graduação em Psicologia de Infância e da Adolescência. Universidade Federal do Paraná, Curitiba, 2004.

FREITAG, B. Prefacio. In: KNETCHEL, M. R. Educação Permanente da Reunificação Alemã a Reflexões Práticas no Brasil. Curitiba: UFPr, 1994. P. $5-15$. 
GONZÁLEZ REY, F. La comunicación educativa: su importancia en el desarrollo integral de la personalidad. In: Comunicación, Personalidad y Desarrollo. La Habana: Pueblo y Educación, 1995. P. 1 27.

. Comunicación, personalidady sujeto: hacia un replanteamiento del desarrollo y el aprendizaje. Disponível em: $<$ http://www.fae.unicamp.br/ br2000/trabs/1280.doc $>$. Acesso em 15.05.2002.

KNETCHEL, M. R. Educação Permanente da Reunificação Alemã a Reflexões Práticas no Brasil. Curitiba: UFPr, 1994.

LANE, S. T. M. O que é Psicologia Social. São Paulo: Brasiliense, 1981.

.; CODO, W. (Org.). Psicologia Social: o homem em movimento. 11. ed. São Paulo: Brasiliense, 1993.

. A Mediação Emocional na Constituição do Psiquismo Humano. In: LANE, S. T. M.; SAWAIA, B. (Org.). Novas Veredas da Psicologia Social. São Paulo: Brasiliense; EDUC, 1995. P. 55 - 63.

PALHARES, P. A. Programa de Extensão Integrar: criando um espaço para o desenvolvimento humano: identificação do perfil e levantamento de interesses Curitiba, 2003. Trabalho Monográfico apresentado à disciplina Monografia II como requisito parcial à conclusão do Curso de Psicologia. Setor de Ciências Humanas, Letras e Artes. Universidade Federal do Paraná, Curitiba, 2003.

RHYNE, J. Arte e Gestalt: padrões que convergem. São Paulo: Summus, 2000.

RILEY, S. Arteterapia para a Família: abordagens integrativas. São Paulo: Summus, 1998. 
ROGERS, N. Facilitating Creativity. In: The Creative Connection: expressive arts as healing. Palo Alto: Science \& Behavior Books, 1993. P. $11-25$.

RIMÉ, B. Le partage social des émotions. In: _ ; SCHERER, K. Textes de base em psycholigie: les emotions. Neuchâtel: Delachaux; Paris: Niestlé, 1993. P. $271-278$.

TATAGIBA, M. C.; FILÁRTIGA, V. Vivendo e Aprendendo com Grupos: uma metodologia construtivista de dinâmica de grupo. Rio de Janeiro: DP\&A, 2001.

VYGOTSKY, L. S. A Formação Social da Mente. 3. ed. São Paulo: Martins Fontes, 1989. 1990.

. La imaginacion y el arte en la infancia. 2. ed. Madrid: AKAL, . Psicologia da Arte. São Paulo: Martins Fontes, 1999.

. A Educação Estética. In: . Psicologia Pedagógica 1. São

Paulo: Martins Fontes, 2001. P. 321 -363. 